\title{
ANALFABETISMO FUNCIONAL: REFLEXÕES SOBRE O DESENVOLVIMENTO EDUCACIONAL NO BRASIL
}

\author{
FUNCTIONAL ANALPHABETISM: REFLECTIONS ON EDUCATIONAL \\ DEVELOPMENT IN BRAZIL
}

\author{
Euzene Mendonça Barbosa Matos ${ }^{1}$ \\ Benedito de Sousa Matos ${ }^{2}$ \\ Francisco Regis Vieira Alves ${ }^{3}$
}

RESUMO: analfabetismo funcional, é caracterizado, quando os alunos escolarizados ainda apresentam dificuldades em buscar, avaliar e organizar informações de modo a aprender, resolver problemas e tomar decisões para a vida. As resultantes desse fator tem gerado a limitação social e intelectual de grande parte da população, e gerado sérios problemas para o desenvolvimento educacional no Brasil. Este artigo busca refletir alguns fatores que implicam no analfabetismo funcional, com a revisão de literatura sobre a conceituação, as políticas educacionais, e os dados estatísticos a respeito do índice de analfabetos funcionais e suas características de identificação no meio social educacional.

Palavras-chaves: Analfabetismo funcional. Currículo. Políticas educacionais.

ABSTRACT: Functional illiteracy is characterized when schooled students still have difficulties in seeking, evaluating and organizing information in order to learn, solve problems and make decisions for life. The results of this factor have created social and intellectual limitations for a large part of the population, and have created serious problems for educational development in Brazil. This article seeks to reflect some factors that imply functional illiteracy, with a literature review on conceptualization,

\footnotetext{
I Instituto Federal de Educação, Ciências e Tecnologia do Estado do Ceará - IFCE. Brasil. Professora Titular do Instituto Federal de Educação, Ciência e Tecnologia do Estado do Ceará - IFCE, Departamento de Educação. Docente dos Cursos de Licenciaturas em Física e Matemática. Líder do Grupo de Estudos e Pesquisas em Educação Aplicada GEPEA/IFCE. E-mail: euzenemcp@gmail.com. ${ }^{2}$ Instituto para o Desenvolvimento da Educação Aplicada- IDEA. Brasil Diretor Executivo do Instituto para o Desenvolvimento da Educação Aplicada- IDEA. Brasil. Pesquisador do Grupo de Estudos e Pesquisas em Educação Aplicada GEPEA/IFCE. benedito.flz@gmail.com.

3 Instituto Federal de Educação, Ciências e Tecnologia do Estado do Ceará - IFCE. Brasil Professor Titular do Instituto Federal de Educação, Ciência e Tecnologia do Estado do Ceará - IFCE, Departamento de Matemática e Física. Bolsista de Produtividade em Pesquisa do Conselho Nacional de Desenvolvimento Científico e Tecnológico - CNPQ/PQ2. Docente Permanente do Mestrado Acadêmico em Ensino de Ciências e Matemática - PGECM/IFCE. Docente Permanente do Mestrado Profissional em Educação Profissional e Tecnológica - PROEPT/IFCE em Rede. Docente Permanente do Doutorado em Rede Região Nordeste-RENOEN. Brasil. E-mail: fregis@ifce.edu.br.
} 
educational policies, and statistical data regarding the functional illiterate index and its identification characteristics in the educational social environment.

Keywords: Functional illiteracy; Curriculum; Educational policies

\section{INTRODUÇÃO}

O analfabetismo funcional é um problema constante no Brasil, e nos leva a refletir sobre as causas e consequências não superadas pelas políticas educacionais adotadas ao longo das últimas décadas.

Os dados de 2019 mostram que temos II,3 milhões de pessoas acima de 15 anos de idade não sabem ler nem escrever, o equivalente a $6,8 \%$ para esta faixa etária. A taxa de analfabetismo para homens de is anos ou mais de idade foi $7 \%$ e para mulheres, 6,6\% (PNAD, 2019).

Assim, indicamos alguns fatores que implicam no analfabetismo funcional, como:

- $\quad$ método de alfabetização

- Estrutura dos sistemas públicos de ensino

- A política de material didático e

- Políticas educacionais para o alinhamento dos níveis de aprendizagem nas escolas.

Sobre a conceituação de alfabetização, neste estudo, adotamos o conceito formalmente estabelecido pelo Ministério da Educação - MEC ao afirmar que "um indivíduo alfabetizado não será aquele que domina apenas rudimentos da leitura e da escrita e/ou alguns significados numéricos, mas aquele que é capaz de fazer uso da língua escrita e dos conceitos matemáticos em diferentes contextos" (INEP, p.i6o, 2015). Nesse sentido, a pessoa é considerada analfabeta funcional, quando torna-se incapaz de ler e utilizar-se da leitura, da escrita e da aritmética em prol de seu próprio desenvolvimento e o da comunidade" (GARCIA, 1990).

Nesse entendimento, foram implementadas várias políticas educacionais com o objetivo de responder aos problemas relacionados ao processo educacional. Políticas estas, que deixaram impressas suas marcas na educação brasileira, mas ainda muito longe de se alcançar verdadeiramente a erradicação do analfabetismo. 
Assim, torna-se necessário as reflexões acerca dos fatores que implicam no analfabetismo no Brasil, repensando as questões sócio, econômica, cultural, e ideológica como parâmetro para análise das intenções postas nos objetivos e na seriedade de acompanhamento das ações pelos gestores do ensino.

Para isso, a revisão da literatura trata sobre os conceitos de analfabetismo, dos dados estatísticos que revelam essa resultante ao longo da história no sistema educacional brasileiro. E ainda, o perfil do analfabetismo no Brasil.

\section{Definição de Analfabetismo Funcional e questões relacionadas}

Os desafios contemporâneos da educação brasileira são identificados através de um número expressivo de alunos que conclui o ensino fundamental e pode ser considerado analfabeto funcional. Isto é, após vários anos de escolarização, estes alunos não conseguem se apropriar das práticas oferecidas pela escola, e muitos, se encontram à margem de um letramento efetivo (CORDEIRO, 20II).

Para o referido autor, o analfabetismo funcional está presente quando esses alunos, mesmo após nove anos de escolarização, apresentam dificuldades em buscar e encontrar informações, compreender, avaliá-las e organizá-las de modo a apreender, resolver problemas, tomar decisões, não só no contexto escolar como em casa, em todo lugar.

Toledo (2009), nos alerta que estamos em uma sociedade letrada, em que o indivíduo não domina a linguagem escrita, e esta, é uma situação delicada para sua inserção em diversas atividades culturais que são valorizadas pela mesma.

Essas dificuldades, presentes dentro e fora das salas de aula, estão relacionadas à questão do letramento ou do alfabetismo funcional que, segundo estudos recentes, refere-se às habilidades de leitura e escrita de textos em diferentes gêneros e funções sociais. Ou seja, a criança e o adolescente aprendem as letras, as sílabas e as palavras no processo inicial de alfabetização, mas não conseguem aprender a fazer uso da palavra escrita de maneira significativa e criativa em seu cotidiano. (TOLEDO, 2009, p. I4).

Podemos analisar que existe um grande sentimento de impotência perante o comportamento destes jovens, pois essas desvantagens influenciam diretamente no nível salarial, consequentemente em sua qualidade de vida, restringindo 
oportunidades por melhores empregos e capacidade intelectual para lidar com os desafios e conflitos da sociedade (TOLEDO, 2009).

Nesse contexto, o Instituto Nacional de Alfabetismo Funcional -INAF (2018) em parceria com o Instituto Paulo Montenegro e a ONG Ação Educativa, analisou através de sua escala, as indicações para estabelecer parâmetros entre a população brasileira entre 15 à 64 anos.

Para o referido Instituto o nível de analfabetismo passou de quatro níveis para cinco, dentre eles citam-se: Analfabeto, Rudimentar, Funcionalmente, Elementar, Intermediário e Proficiente, na qual aperceberam-se das diferenças entre os analfabetos.

Veja abaixo que grupos são esses e confira os principais pontos de cada um:

Analfabeto: não consegue realizar tarefas simples como a leitura de frases e palavras;

Rudimentar: consegue identificar informações explícitas e literais em textos simples, compara, lê e escreve números familiares e consegue identificar os maiores e os menores, resolve problemas matemáticos simples e estabelece relações entre grandezas e unidades de medida, reconhece sinais de pontuação e sabe suas respectivas designações e funções.

Elementar: seleciona unidades de informação em textos de extensão média, resolve problemas envolvendo operações matemáticas básicas com números da ordem do milhar, compara ou relaciona informações numéricas ou textuais apresentadas em gráficos ou tabelas, sabe reconhecer o que significa uma representação gráfica de direção e/ou um sentido de uma grandeza;

Intermediário: consegue identificar informações literais em vários tipos de texto, inclusive nos científicos, resolve problemas envolvendo operações matemáticas complexas com números da ordem dos milhões, consegue interpretar diversos tipos de textos e elaborar sínteses, reconhece o efeito estético ou o efeito de sentido de opções lexicais ou sintáticas, de figuras de linguagem ou de sinais de pontuação;

Proficiente: produz textos de maior complexidade (mensagem, descrição, exposição ou argumentação), interpreta tabelas e gráficos envolvendo mais de duas 
variáveis, consegue resolver situações-problema relacionadas com tarefas de contextos diversos.

São considerados analfabetos funcionais, os indivíduos que integram os grupos “Analfabeto" e "Rudimentar".

Assim, compreendemos que a falta da leitura e da escrita, da habilidade matemática, da interpretação e expressão, são consequências de vários fatores que ao longo do tempo foram se agravando sem resoluções eficientes para tratar dos fatores que, condicionam as condições de desenvolvimento do indivíduo. Dentre esses fatores, passaremos, a seguir, a análise dos métodos de alfabetização, que tem sido visto como um dos causadores dessa problemática.

\section{O Analfabetismo Funcional e os métodos de alfabetização no Brasil}

Até a segunda metade do século XIX, a alfabetização no Brasil foi marcada pela utilização de algum material impresso sob a forma de livros para fins de ensino de leitura, editados ou produzidos na Europa. Usualmente, porém, iniciava-se o ensino da leitura com as chamadas "cartas de ABC" e depois se liam e se copiavam documentos manuscritos. Nessa época, iniciavam-se a utilização de métodos de marcha sintética (da "parte” para o "todo"): da soletração (alfabético), partindo do nome das letras; fônico (partindo dos sons correspondentes às letras); e da silabação (emissão de sons), partindo das sílabas (MORTATTI, 2006). Ou seja, o ensino deverse-ia, assim, iniciar com a leitura e a apresentação das letras e seus nomes (método da soletração/alfabético), ou de seus sons (método fônico), ou das famílias silábicas (método da silabação), sempre de acordo com certa ordem crescente de dificuldade.

Posteriormente, reunidas as letras ou os sons em sílabas, ou conhecidas as famílias silábicas, ensinava-se a ler palavras formadas com essas letras e/ou sons e/ou sílabas e, por fim, ensinavam-se frases isoladas ou agrupadas. Quanto à escrita, esta se restringia à caligrafia e ortografia, e seu ensino, à cópia, ditados e formação de frases, enfatizando-se o desenho correto das letras.

Segundo a mesma autora, foi a partir de 1890 , com a implementação da reforma da instrução pública no estado de São Paulo, que ocorreu a reorganização da Escola Normal de São Paulo e a criação da Escola-Modelo Anexa; em I896, foi criado o Jardim da Infância nessa escola. 
A partir dessa primeira década republicana, professores formados por essa escola normal passaram a defender programaticamente o método analítico para o ensino da leitura e disseminaram-no para outros estados brasileiros, por meio de "missões de professores" paulistas. Especialmente mediante a ocupação de cargos na administração da instrução pública paulista e a produção de instruções normativas, de cartilhas e de artigos em jornais e em revistas pedagógicas, esses professores contribuíram para a institucionalização do método analítico, tornando obrigatória sua utilização nas escolas públicas paulistas. Embora a maioria dos professores das escolas primárias reclamasse da lentidão de resultados desse método, a obrigatoriedade de sua utilização no estado de São Paulo perdurou até se fazerem sentir os efeitos da “autonomia didática” proposta na "Reforma Sampaio Dória” (Lei 1750, de 1920).

Retomando a Mortatti (2006), a autora revela, que no método analítico, o ensino da leitura deveria ser iniciado pelo "todo", para depois se proceder à análise de suas partes constitutivas. No entanto, diferentes se foram tornando os modos de processuação do método, dependendo do que seus defensores consideravam o "todo": a palavra, ou a sentença, ou a "historieta" (conjunto de frases relacionadas entre si por meio de nexos lógicos).

A partir desse momento, a autora revela, o início de uma acirrada disputa entre partidários do então novo e revolucionário método analítico para o ensino da leitura e os que continuavam a defender e utilizar os tradicionais métodos sintéticos, especialmente o da silabação. Foi também ao longo desse momento, já no final da década de I9Io, que o termo "alfabetização" começa a ser utilizado para se referir ao ensino inicial da leitura e da escrita.

Vale destacar, que a "Reforma Sampaio Dória" e de novas urgências políticas e sociais, a partir de meados da década de 1920 , trouxeram também a "autonomia didática”, aumentando, assim, as resistências dos professores quanto à utilização do método analítico, que passava a ser ameaçado por novas propostas de solução para os problemas do ensino e aprendizagem iniciais da leitura e da escrita.

Assim, os defensores do método analítico continuaram a utilizá-lo e a propagandear sua eficácia. No entanto, buscando conciliar os dois tipos básicos de métodos de ensino da leitura e escrita (sintéticos e analíticos), em várias tematizações 
e concretizações das décadas seguintes, passaram-se a utilizar: métodos mistos ou ecléticos (analítico-sintético ou vice-versa), considerados mais rápidos e eficientes (MORTATTI, 2006).

A mesma autora afirma, que essa fase se estende até aproximadamente o final da década de 1970, onde é fundado uma outra nova tradição no ensino da leitura e da escrita: a alfabetização sob medida, de que resulta o como ensinar subordinado à maturidade da criança a quem se ensina; as questões de ordem didática, portanto, encontram-se subordinadas às de ordem psicológica.

Outro momento marcante na história da alfabetização, foi na década de 1980, quando essa tradição passou a ser sistematicamente questionada, em decorrência de novas urgências políticas e sociais que se fizeram acompanhar de propostas de mudança na educação, a fim de se enfrentar, particularmente, o fracasso da escola na alfabetização de crianças.

Essa foi a problemática que impulsionou a busca de soluções para esse problema. Resultando, assim, a introdução do pensamento construtivista no Brasil, baseado nos teóricos Jean Piaget (1896-1980), Celetim Freinet (1896-1966), e Emilia Ferreiro.

A década de 1980, também foi marcada pela emergência do pensamento interacionista de Lev Vygotsky (1896-1934) em alfabetização, que foi gradativamente ganhando destaque e gerando uma espécie de disputa entre seus defensores e os do construtivismo.

Ocorre que, a prática construtivista, somada a outros fatores, tem sido um verdadeiro fracasso nos índices educacionais. Um dos motivos é que o método leva em consideração que a criança ao iniciar sua alfabetização na escola já tenha adquirido conhecimentos prévios, que continue a ser estimulada, em seus estudos, fora da escola e que tenha acesso a informações e tecnologias adequadas as suas necessidades.

Outra exigência do método construtivista é que as salas de aulas devem ser adequadas com material didático específico para a construção do conhecimento. Exigência esta, que não condiz com a realidade educacional de nossas escolas, que não têm em sua maioria estrutura física e pedagógica apropriada para favorecer a execução das atividades educativas. 
$\mathrm{Na}$ sequência desses fatores destaca-se a pratica dos professores construtivistas no cotidiano na sala de aula, a orientação é que os professores assumam uma postura de mediador do conhecimento, deixando seus alunos livres para decidirem o querem aprender baseados na curiosidade. Tal situação torna-se preocupante, pelo fato de não haver um planejamento adequado para os assuntos que possam vir a ser tratados na aula.

Outro fator que merece destaque, é a forma que se organiza a sala de aula no ensino construtivistas associado ao interacionismo, ou seja, os alunos que se sobressaem melhor e avançam no conhecimento, devem ficar sempre sentados em fileiras ao lado de um coleguinha que geralmente não consegue acompanhar o aprendizado junto com o resto da turma. Tal situação acaba por desmotivar o aluno que se destaca por aprender com mais rapidez e que anseia por mais conhecimento, pois precisa ajudar seu colega e professora na evolução do aluno necessitado de atenção. Isso implica, na pratica do professor, que não terá a preocupação em buscar outros métodos que possam vir atender as necessidades dos que ainda não conseguiram reter o conhecimento.

E ainda, outro ponto inquietante, é o números de alunos por sala de aula. No ensino sócio construtivista o professor precisa acompanhar seus alunos individualmente, e isso é inviável numa sala de aula com mais de 30 alunos.

$\mathrm{Na}$ verdade, existe uma multiplicidade de problemas relacionados ao ensino inicial da leitura e escrita, as dificuldades decorrentes, em especial, da ausência de uma "Didática construtivista”, que oportunamente, vêm abrindo espaço para a tentativa, por parte de uma boa representatividade de pesquisadores, em apresentar "novas propostas de alfabetização baseadas em antigos métodos, como os de marcha sintética (MORATTI, 2006), e a alfabetização fônica defendida por Fernado Capovilla.

Trata-se de um método, que consiste no aprendizado através de fonemas e grafemas, assegurando, primeiramente o aprendizado do alfabeto, e progressivamente o domínio do conhecimento ortográfico através de textos elaborados, especificamente, para esse fim (CAPOVILLA, 2006).

Nessa compreensão, também destaca-se que a consciência fonológica consiste da consciência mais geral dos sons, a consciência fonêmica corresponde à habilidade 
de identificar os sons que constituem as palavras, ou seja, é "o entendimento de que cada palavra falada pode ser concebida como uma sequência de fonemas" (BRASIL, 2007, p.4I-42).

Desse modo, a literatura nos proporciona as evidências que a discussão sobre o analfabetismo funcional não pode se limitar apenas a essas dimensões, mas considerar que o método de ensino é relevante para o processo de conhecimento.

\title{
O analfabetismo funcional e a estrutura dos sistemas públicos de ensino
}

A estrutura se refere aos prédios, instalações físicas, como bibliotecas, laboratórios, sala de aula, quadra, banheiro, em que o funcionamento, depende dessa estrutura. Ou seja, uma escola em funcionamento tem a presença de funcionários, professores, alunos, gestores, coordenadores, etc. E para o bom funcionamento da escola é preciso o compromisso de todos com a aprendizagem, o oposto, não favorece um bom funcionamento. Isto implica na qualidade do ensino, que a escola se propõe a oferecer a seus alunos, e quando esta questão estrutural não é bem resolvida, toda a comunidade escolar é prejudicada.

Se por um lado, é importante um ambiente bem estruturado e saudável para se obter melhores resultados no processo ensino aprendizagem. Por outro lado, estudar e trabalhar num ambiente em condições deficientes pode interferir negativamente na produtividade dos profissionais e na desmotivação dos alunos. Como nos descreve Davis,

\begin{abstract}
A escola é mais do que quatro paredes, é clima, espirito de trabalho, produção de aprendizagem, relações sociais de formação de pessoas. $O$ espaço tem que gerar ideias, sentimentos, movimentos no sentido da busca do conhecimento, tem que despertar interesse em aprender, além de ser algo alegre, aprazível e confortável, tem que ser pedagógico (DAVIS, 1993, p.53).
\end{abstract}

Dessa forma, o ambiente escolar bem estruturado física e pedagogicamente pode contribuir, principalmente, com os problemas relacionados ao analfabetismo funcional.

Como nos alerta Moran (2000) sobre as seguintes variáveis:

Uma organização inovadora, aberta, dinâmica, com um projeto pedagógico coerente, alerto, participativo; com infraestrutura adequada, atualizada, confortável; com tecnologias acessíveis, rápidas e renovadas. Uma organização que congregue docentes bem preparados intelectual, emocional, 
comunicacional e eticamente; bem remunerados, motivados e com boas condições profissionais, onde haja circunstâncias favoráveis a uma relação efetiva com alunos que facilite conhecê-los acompanhá-los, orientá-los (MORAN, 2000, p. 14).

Assim, passemos refletir, no próximo ponto, acerca da falta de material didático adequado para o ensino básico e médio como um fator determinante para a qualidade do ensino.

\section{O analfabetismo funcional e a política do material didático}

O Decreto $\mathrm{N}^{\circ}$ 9.099, de 18 de julho de 2017 define que os Programas relacionados a livro foram unificados. O PNLD passou a significar Programa Nacional do Livro e do Material Didático, pois além de livros passou a distribuir livros literários - funções antes atribuída ao Programa Nacional Biblioteca na Escola (PNBE). E ainda, a dimensão do Programa passou a atender, a partir do PNLD 2019, a Educação Infantil e as instituições comunitárias, confessionais ou filantrópicas sem fins lucrativos.

No tocante a obtenção dos materiais didáticos, foi estabelecido que o processo ocorrerá de forma periódica e regular para atender cada uma das etapas e segmentos:

- PNLD 2018 atendeu os anos do Ensino Médio;

- PNLD 2019 foi destinado à Educação Infantil e aos Anos Iniciais do Ensino Fundamental;

- PNLD 2020 diz respeito a aquisição e distribuição para os Anos Finais do Ensino Fundamental.

Com a homologação da Base Nacional Comum Curricular (BNCC), um dos objetivos do PNLD passou a ser "apoiar a implementação da BNCC". Esse apoio à Base se forma no diálogo que os livros didáticos e literários precisam ter com o documento, principalmente com suas especificidades.

Destaca-se, que a participação dos professores na seleção dos livros continua. E por ser uma escolha realizada de maneira democrática e autônoma pelas instituições de ensino, preocupa-nos os critérios adotados para a realização dessa escolha. Isto porque, a escola não possui apenas o papel de ensinar conceitos técnicos e intelectuais, mas também conceitos morais, que muitas vezes são transmitidos com caráter extremamente ideológico (OLIVEIRA, 2014). 
A revisão de literatura nos aponta que os conteúdos presentes nos livros didáticos necessitam de uma reflexão teórica com ações pedagógicas de acompanhamento mais eficazes, pois a realidade social tem revelado manifestações concretas da ideologia trabalhada ao longo das últimas décadas no contexto educacional. Isso implica, nos resultados negativos apresentados nos índices e déficit de aprendizagem e posturas reacionárias por grande parte dos alunos no trato de questões sócio, políticas e culturais.

De acordo com o Ministério da Educação (MEC), todo o processo do PNLD se inicia com a adesão das escolas ao programa, passando pela publicação dos editais e terminando na distribuição e recebimento dos materiais didáticos. A adesão ocorre a partir da manifestação formal das escolas com o material que pretende receber.

Todo o processo começa, com a publicação de um edital, que especifica os elementos que devem estar presentes nos materiais didáticos e define todo o processo do Programa. Seguindo o prazo estabelecido no edital, as editoras interessadas inscrevem suas obras no PNLD.

Considerando que o PNLD objetiva garantir o padrão de qualidade do material, as obras inscritas passam por uma severa avaliação. Não ficou claro em nossas leituras se o padrão estabelecido para essa avaliação, também inclui a análise dos conteúdos, conceitos, imagens e posturas dos autores nas obras.

O MEC divulga que nessa etapa, os especialistas encarregados em analisar os materiais elaboram resenhas dos livros aprovados, que são disponibilizadas no formato de guia para as escolas. Esses guias orientam a escolha do livro e podem ser consultados nos portais on-line do MEC. Posteriormente, diretores e professores, após analisarem os guias dos livros, formalizam a escolha dos materiais que a escola deseja receber via internet. O FNDE adquire os livros solicitados pelas escolas e as editoras ficam encarregadas da produção. Diferenças entre as obras escolhidas e as recebidas podem ocorrer, especialmente em decorrência do processo de unificação tratado anteriormente, ou caso o FNDE não consiga concluir a negociação com a editora originalmente escolhida. 
Sobre a qualidade dos livros físicos é assegurada durante todo o processo de produção do material. Os livros são transportados pelos Correios diretamente das editoras e distribuídos. É uma operação gigantesca, que, todo ano, envolve a distribuição de mais de 150 milhões de livros. A meta é sempre a mesma: garantir que o livro chegue antes do início das aulas.

O PNLD 2019, definiu que a utilização dos livros será de 4 anos consecutivos, o que significa que o aluno deve devolver o material ao final do período letivo, com exceção dos livros consumíveis. Quanto ao retorno dos materiais, tem-se 90\% de devolução como meta para o PNLD. Para contornar as oscilações entre número de alunos e número de livros, o remanejamento ocorre, equilibrando o número de exemplares por escola e garantindo que todos os alunos possuam livros didáticos.

Assim, devido a lacuna de trabalhos científicos a esse respeito, torna-se salutar a busca de conhecimentos aprofundados acerca dos métodos, do elenco de temas, da influência dos conceitos e imagens apresentadas nos livros didáticos, com o compromisso de um trabalho coerente, contextualizado, e sem vertentes politicas

partidárias. Tal sugestão, fundamenta-se no respeito que se deve ao estudante em processo de alfabetização e adolescentes que estão na fase de construção de conceitos e formação de sua personalidade.

\section{O analfabetismo funcional e as políticas educacionais de alinhamento dos níveis de aprendizagem nas escolas}

O estudo das políticas educacionais, especificamente, de alinhamento dos níveis de aprendizagem e seus desdobramentos na escola e no processo de ensinoaprendizagem, são bem complexas. Se por um lado, as demandas sociais decorrentes de transformações na economia, no mundo do trabalho, nas relações sociais, nos meios de comunicação e informação, tem afetado o planejamento das ações educativas, nomeadamente, os currículos, as formas de aprender dos alunos. Por outro lado, às escolas têm assumido diferentes sentidos para suas funções sócio educativas solidificados nas ações políticas pedagógicas, gerando conflitos sobre essas funções entre pesquisadores, professores, e demais gestores educacionais. 
No campo acadêmico, por exemplo, alguns pesquisadores têm apontado a tendência de atribuir às escolas um acúmulo de objetivos, levando-as a assumir atribuições que são de responsabilidade de outras instâncias sociais (SACRISTÁN, 2000; LIBÂNEO, 2011a; NÓVOA, 2009).

Trata-se de ações de cidadania planejadas para assistir e responsabilizar-se pela comunidade escolar, com um certo toque de assistencialismo. Como explica Nóvoa (2009)

\footnotetext{
Um dos grandes perigos dos tempos actuais é uma "escola a duas velocidades": por um lado, uma escola concebida essencialmente como um centro de acolhimento social, para os pobres, com uma forte retórica da cidadania e da participação; por outro lado, uma escola claramente centrada na aprendizagem, e nas tecnologias, destinada a formar os filhos dos ricos (NÓVOA 2009, p. 26)
}

Esse estreito vínculo, além de ser uma estratégia que faz parte das ações pedagógicas da escola para minimizar os problemas sócio educativos, refletem a fragilidade das mesmas em assumir responsabilidades junto aos pais e responsáveis dos alunos sem que tenham condições necessárias para esse fim. As orientações a esse respeito foram emanadas, pela Conferência Mundial sobre Educação para Todos, realizada no ano de 1990 em Jomtien, Tailândia, que, por sua vez, tem direcionado as referidas políticas educacionais nos últimos vinte anos. Libâneo (2011a) não ignora que numa sociedade marcada pela pobreza e violência é quase impossível não concordar que a escola possui, também, certas funções assistenciais.

A linha histórica nos revela que foram várias iniciativas tomadas pelo governo federal em conjunto com as escolas dentre as quais: a Campanha de Educação de Adolescentes e Adultos (1947, Governo Eurico Gaspar Dutra); Campanha Nacional de Erradicação do Analfabetismo (1958, Governo Juscelino Kubitschek); Movimento de Educação de Base (1961, criado pela Conferência Nacional de Bispos do BrasilCNBB); Programa Nacional de Alfabetização, valendo-se do método Paulo Freire (1964, Governo João Goulart); Movimento Brasileiro de Alfabetização - Mobral (ı9681978, Governos da Ditadura Militar); Fundação Nacional de Educação de Jovens e Adultos- Educar (1985, Governo José Sarney); Programa Nacional de Alfabetização e Cidadania-Pnac (1990, Governo Fernando Collor de Mello); Declaração Mundial de Educação para Todos (assinada, em 1993, pelo Brasil em Jomtien, Tailândia); Plano 
Decenal de Educação para Todos (1993, Governo Itamar Franco) e, ainda, o Programa de Alfabetização Solidária (1997, Governo Fernando Henrique Cardoso), Brasil Alfabetizado (2003, Governo Luiz Inácio Lula da Silva), o Pacto Nacional pela Alfabetização na Idade Certa - Pnaic (2012, Governo Dilma Rousseff). E o Programa Tempo de Aprender (2020, Jair Messias Bolsonaro).

Destacamos que esse último denominado “Tempo de Aprender”, é um Programa de alfabetização abrangente, cujo propósito é enfrentar as principais causas das deficiências da alfabetização no país. Entre elas, destacam-se: déficit na formação pedagógica e gerencial de docentes e gestores; falta de materiais e de recursos estruturados para alunos e professores; deficiências no acompanhamento da evolução dos alunos; e baixo incentivo ao desempenho de professores alfabetizadores e de gestores educacionais.

Para uma melhor compreensão dos índices estatísticos acerca do analfabetismo funcional no Brasil, apresentamos abaixo, a tabela I do do INAF (2018) mostra a evolução das médias de proficiências de cada um dos cinco níveis no período de 200I-2002 a 2018, corroborando a consistência da escala ao longo do tempo, o que assegura a comparabilidade dos dados históricos do indicador, como segue:

Tabela 1 - Proficiências médias por nível de Alfabetismo

\begin{tabular}{l|c|c|c|c|c|c|c|c|c}
\hline & $\mathbf{2 0 0 1 -}$ & $\mathbf{2 0 0 2 -}$ & $\mathbf{2 0 0 3 -}$ & $\mathbf{2 0 0 4 -}$ & $\mathbf{2 0 0 7}$ & $\mathbf{2 0 0 9}$ & $\mathbf{2 0 1 1}$ & $\mathbf{2 0 1 5}$ & $\mathbf{2 0 1 8}$ \\
\hline Analfabeto & 33,3 & 33,5 & 34,0 & 33,8 & 34,7 & 31,3 & 29,3 & 35,1 & 31,5 \\
Rudimentar & 76,6 & 76,5 & 75,8 & 75,8 & 76,3 & 78,2 & 78,2 & 77,9 & 77,7 \\
Elementar & 106,8 & 106,6 & 106,5 & 106,8 & 108,0 & 108,3 & 108,1 & 107,6 & 108,1 \\
Intermediário & 127,9 & 127,6 & 127,6 & 127,9 & 128,7 & 127,3 & 126,8 & 126,8 & 127,2 \\
Proficiente & 148,7 & 148,7 & 148,7 & 148,6 & 148,9 & 147,3 & 146,5 & 146,0 & 147,0 \\
\hline Total população & 99,1 & 98,7 & 99,6 & 100,2 & 102,8 & 106,4 & 106,1 & 105,1 & 104,8 \\
\hline
\end{tabular}

Fonte: Inaf 2001-2018

Numa escala mais usual de o a ro e tomando como referência os dados de 2018, pode-se dizer que as pessoas classificadas pelo INAF, como Analfabetas tirariam a nota I,6; aquelas classificadas em nível Rudimentar receberiam nota 3,9; os que são caracterizados como tendo Alfabetismo em nível Elementar, 5,5; os que estão no nível 
Intermediário, 6,6; e os Proficientes, 7,4. Como se pode observar as notas seriam consistentes ao longo de todo o período (INAF, 2018).

$\mathrm{Na}$ tabela 2 do INAF (2018), foi possível identificar que, os resultados obtidos ao longo de mais de uma década mostram uma significativa redução do número de Analfabetos, caindo de 12\%, em 2001-2002 para 4\% em 2015, embora os dados desta última edição sinalizem uma inflexão nessa tendência, indicada por um novo aumento desse patamar em 2018. Ao longo dos anos, houve ainda uma redução da proporção de brasileiros que conseguem fazer uso da leitura da escrita e das operações matemáticas em suas tarefas do cotidiano apenas em nível Rudimentar (de 27\% em 2001-2002 para um patamar estabilizado de pouco mais de $20 \%$ desde 2009). Indivíduos classificados nesses dois níveis de Alfabetismo compõem um grupo denominado pelo Inaf como Analfabetos Funcionais. Os Analfabetos Funcionais - equivalentes, em 2018, a cerca de 3 em cada io brasileiros - têm muita dificuldade para fazer uso da leitura e da escrita e das operações matemáticas em situações da vida cotidiana, como reconhecer informações em um cartaz ou folheto ou ainda fazer operações aritméticas simples com valores de grandeza superior às centenas. Como apresenta a Tabela 2 abaixo:

Tabela 2 - Níveis de alfabetismo no Brasil conforme o Inaf (2001-2018)

\begin{tabular}{|c|c|c|c|c|c|c|c|c|c|}
\hline Nível & $\begin{array}{l}2001 \\
2002 \\
\end{array}$ & $\begin{array}{l}2002 \\
2003 \\
\end{array}$ & $\begin{array}{l}2003 \\
2004 \\
\end{array}$ & $\begin{array}{l}2004 \\
2005 \\
\end{array}$ & 2007 & 2009 & 2011 & 2015 & 2018 \\
\hline BASE & 2000 & 2000 & 2001 & 2002 & 2002 & 2002 & 2002 & 2002 & 2002 \\
\hline Analfabeto & $12 \%$ & $13 \%$ & $12 \%$ & $11 \%$ & $9 \%$ & $7 \%$ & $6 \%$ & $4 \%$ & $8 \%$ \\
\hline Rudimentar & $27 \%$ & $26 \%$ & $26 \%$ & $26 \%$ & $25 \%$ & $20 \%$ & $21 \%$ & $23 \%$ & $22 \%$ \\
\hline Elementar & $28 \%$ & $29 \%$ & $30 \%$ & $31 \%$ & $32 \%$ & $35 \%$ & $37 \%$ & $42 \%$ & $34 \%$ \\
\hline Intermediário & $20 \%$ & $21 \%$ & $21 \%$ & $21 \%$ & $21 \%$ & $27 \%$ & $25 \%$ & $23 \%$ & $25 \%$ \\
\hline Proficiente & $12 \%$ & $12 \%$ & $12 \%$ & $12 \%$ & $13 \%$ & $11 \%$ & $11 \%$ & $8 \%$ & $12 \%$ \\
\hline Total $^{2}$ & $100 \%$ & $100 \%$ & $100 \%$ & $100 \%$ & $100 \%$ & $100 \%$ & $100 \%$ & $100 \%$ & $100 \%$ \\
\hline $\begin{array}{l}\text { Analfabeto } \\
\text { Funcional* }\end{array}$ & $39 \%$ & $39 \%$ & $37 \%$ & $37 \%$ & $34 \%$ & $27 \%$ & $27 \%$ & $27 \%$ & $29 \%$ \\
\hline $\begin{array}{l}\text { Funcionalmente } \\
\text { Alfabetizados* }\end{array}$ & $61 \%$ & $61 \%$ & $63 \%$ & $63 \%$ & $66 \%$ & $73 \%$ & $73 \%$ & $73 \%$ & $71 \%$ \\
\hline
\end{tabular}

Fonte: Inaf 2001-2018

Pelo que foi apresentado, percebe-se que o analfabetismo funcional é um dos fatores externos mais preocupantes na realidade educacional brasileira. Ao nos interrogarmos sobre suas causas sentimos a necessidade de buscar os motivos que afetam diretamente com os estudos de uma pessoa desde o início de sua vida escolar. 
Portanto, vale a nossa preocupação em buscar novas metodologias e políticas educacionais que venham atender verdadeiramente as necessidades do processo ensino aprendizagem, bem como, a otimização do tempo e planejamento nas escolas voltados para a abordagem do conhecimento sistemático de nossos alunos.

\section{CONSIDERAÇÕES FINAIS}

O cenário descrito neste artigo, nos possibilitou realizar reflexões e levantar várias problemáticas relativas ao processo educacional.

Ao destacarmos os fatores que implicam negativamente no processo ensino aprendizagem, ficou perceptível a necessidade de compromisso e condições necessárias para a execução das propostas. Isto porque, os estudos sobre o analfabetismo funcional é complexo e envolve ações políticas e pedagógicas.

Os estudos a esse respeito nos preocupa, pois é fato, que o analfabetismo funcional acaba excluindo o indivíduo da sociedade e do próprio convívio escolar. $\mathrm{E}$ ainda, o mais grave é não poder se adequar plenamente das exigências do mercado de trabalho. Outro fator que nos chama a atenção, é o nível de escolaridade e cultura familiar, pois o acompanhamento e participação dos pais na vida escolar dos filhos é fundamental para uma boa formação.

Assim, a lição que tomamos com esse artigo nos leva a compreensão de que o processo educacional envolve a tomada de consciência da realidade vivida, somada a intenção de mudança que nos motiva.

\section{REFERÊNCIAS BIBLIOGRÁFICAS}

BRASIL. Constituição da República Federativa do Brasil. Brasília: Senado Federal, 1988.

- Instituto Nacional de Estudos e Pesquisas Educacionais Anísio Teixeira (Inep). Plano Nacional de Educação PNE 2014-2024: Linha de Base. Brasília, DF: INEP, 2015. $404 \mathrm{p}$.

Ministério da Educação. Guia de livros didáticos PNLD 2008: Ciências / Ministério da Educação. - Brasília: MEC, 2007.

. Presidência da República. Decreto no 9.099, de 18 de julho de 2017. Disponível em: http://www.planalto.gov.br/ccivil_03/_ato2015-2018/2017/decreto/D9099.htm. Acesso em: 22 abril. 2021.

CAPOVILLA, F. Transtornos de Aprendizagem. São Paulo: Memnon, 2006. 
CORDEIRO, R. B. G. Desafios contemporâneos da educação brasileira letramento(s). In: SIMPÓSIO INTERNACIONAL DE ESTUDOS DE GÊNEROS TEXTUAIS, 6, Natal. Anais. Natal, 2orr.

DAVIS, Claudia. Oliveira. Psicologia na educação. São Paulo: Cortez, 1993.

GARCIA, M. Um saber sem escrita: visão de mundo do analfabeto. Cadernos de Pesquisa, São Paulo, v. 75, p. 15-24, 1990.

IBGE. Pesquisa Nacional por Amostra de Domicílios -Síntese de Indicadores 2019. Rio de Janeiro, 2019. Disponível em: 〈http:www.ibge.gov.br 〉. Acesso em: 3 maio de 2021.

INSTITUTO PAULO MONTENEGRO. Indicador de alfabetismo funcional - $O$ que é Inaf. São Paulo, 20r8. Disponível em: http://www.ipm.org.br. Acesso em: 3 março 2020 .

LIBÂNEO, J. C. A formação de professores no curso de pedagogia e o lugar destinado aos conteúdos do ensino fundamental: que falta faz o conhecimento do conteúdo a ser ensinado às crianças? In: SILVA, M. A.; BRZEZINSKI, I. (Orgs.). Formar professores - pesquisadores: construir identidades. Goiânia: Ed. da PUC Goiás, 2orra.

MORAN, J.M.; Novas tecnologias e mediação pedagógica. Campinas, SP: Papirus, 2000 .

NÓVOA, A. Professores: imagem do futuro presente. Lisboa: Educa, 2009.

MORTATTI, M. R. L. Um balanço crítico da "Década da Alfabetização" no Brasil. Caderno Cedes, Campinas, v. 33, n. 89, p. 15-34, 2013. Disponível em: $\langle$ http://www.scielo.br/pdf/ccedes/v33n89/ao2v33n89.pdf $\rangle$. Acesso em: 3 maio de 2021.

OLIVEIRA, L. B. Educação no campo: Mobral no meio rural de Uberlândia. 2011. Disponível em: <file:///G://EDUCA\%C3\%87\%C3\%83O\%20NO\%20CAMPO\%2oMOBRAL.pdf $>$. Acesso em: I de maio de 202I.

SACRISTÁN, J. G. O currículo: os conteúdos dos ensino ou uma análise prática? In:

SACRISTÁN, J. G.; PÉREZ GÓMES, A. I. Compreender e transformar o ensino. Trad. Ernani F. da Fonseca Rosa. Porto Alegre: Artmed, 2000.

SÃO PAULO. Lei n. 1750, de 8 de dezembro de 1920. Reforma a instrução pública do estado de São Pulo. Disponível em: http://www.al.sp.gov.br/repositorio/legislacao/lei/r920/lei-I750-o8.12.1920.html. Acesso em 8 maio de 202I. 
TOLEDO, L. S. Alfabetismo funcional, linguagem e inclusão social. Leituras Transdisciplinares de Telas e Textos 2009. Belo Horizonte, v.5, n.Io, p. 22. Disponível em: <file:///C:/Users/hpi/Downloads/I0047-28783-I-SM.pdf >. Acesso em: I2 de abril de 202I. 